\title{
The maturation of cortical interneuron diversity: how multiple developmental journeys shape the emergence of proper network function Rosa Cossart
}

\begin{abstract}
If the classical functional attribute of cortical GABAergic interneurons is to mediate synaptic inhibition in the adult cortex, it is becoming evident that their major task is instead to shape the spatio-temporal dynamics of the network oscillations that support most brain functions. This complex function involves a division of labour between morpho-physiologically diverse interneuron subtypes. Both the central network function and the bewildering heterogeneity of the interneuron population are especially emphasized during cortical development: at early postnatal stages, a single GABAergic neuron can efficiently pace the activity of hundreds of other cells, whereas some interneuron subtypes are still poorly developed. Given the role of coherent activity in brain development, this confers to GABAergic interneurons a major role in the proper maturation of cortical networks.
\end{abstract}

\section{Address}

INMED, INSERM U901, Université de la Méditerranée, Parc Scientifique de Luminy, BP.13, 13273 Marseille Cedex 9, France

Corresponding author: Cossart, Rosa (cossart@inmed.univ-mrs.fr)

\section{Introduction}

It is now becoming increasingly evident that a selective disruption of cortical GABAergic interneuron development, resulting from either genetic or epigenetic factors, is related to many neurological disorders like epilepsy, mental retardation, autism or even schizophrenia $\left[1-7,8^{\bullet}\right]$. Interestingly, the developmental loss of restricted interneuron subpopulations [6,9] or subtle functional alterations of interneuron physiological properties [4] were shown to have dramatic consequences often leading to the initiation of seizure activity at early postnatal stages. Since epilepsy can be easily conceived as the direct outcome of an inhibition deficit due to interneuron loss, understanding other more complicated brain disorders certainly indicates more elaborate cellular mechanisms and interpretations.

Two nonexclusive explanations account for the multiple impacts on brain operation of an altered development of GABAergic neurons. First, in addition to providing inhibition, GABAergic interneurons are the substrate of several nonlinear network operations required to support high brain functions. To this aim, GABAergic interneurons come in many flavors, each of them designed to carry a specific circuit task and bear the variety of network oscillations generated by mature cortical networks [10]. The second explanation for the multiple consequences of an abnormal maturation of subpopulations of GABAergic cells is that aberrant development is not restricted to the affected microcircuits but rather affects the entire network. Indeed, during brain development, there is an almost continuous crosstalk between GABAergic interneurons and the networks they integrate into, whereby the same population that supports adult network function also controls the generation of early network patterns which in turn contribute to network development creating a feedback loop.

Until recently, investigating the functional maturation of GABAergic microcircuits was seriously hampered for one major reason: developing interneuron subtypes cannot be readily identified and classified as they have not yet reached their mature neurochemical and morpho-physiological attributes (Figure 1). The advance in novel imaging and genetic strategies to dissect the functional organization of developing GABAergic neurons has opened a new era for the investigation of GABA neuron development. We will review recent work aiming at understanding how the functional diversity of this major neuronal population develops in parallel with the maturation of coherent network patterns.

\section{Interneurons have a crucial early network function that spans throughout an extended developmental period}

At adult stages it is now well established that the major function of cortical GABAergic interneurons is to organize in time and space the generation of most network oscillations associated with behavioural and cognitive brain functions $\left[10,11^{\bullet}, 12^{\bullet \bullet}\right]$. This central network function of the GABAergic interneuron population is emphasized during cortical development in several ways. First, the 


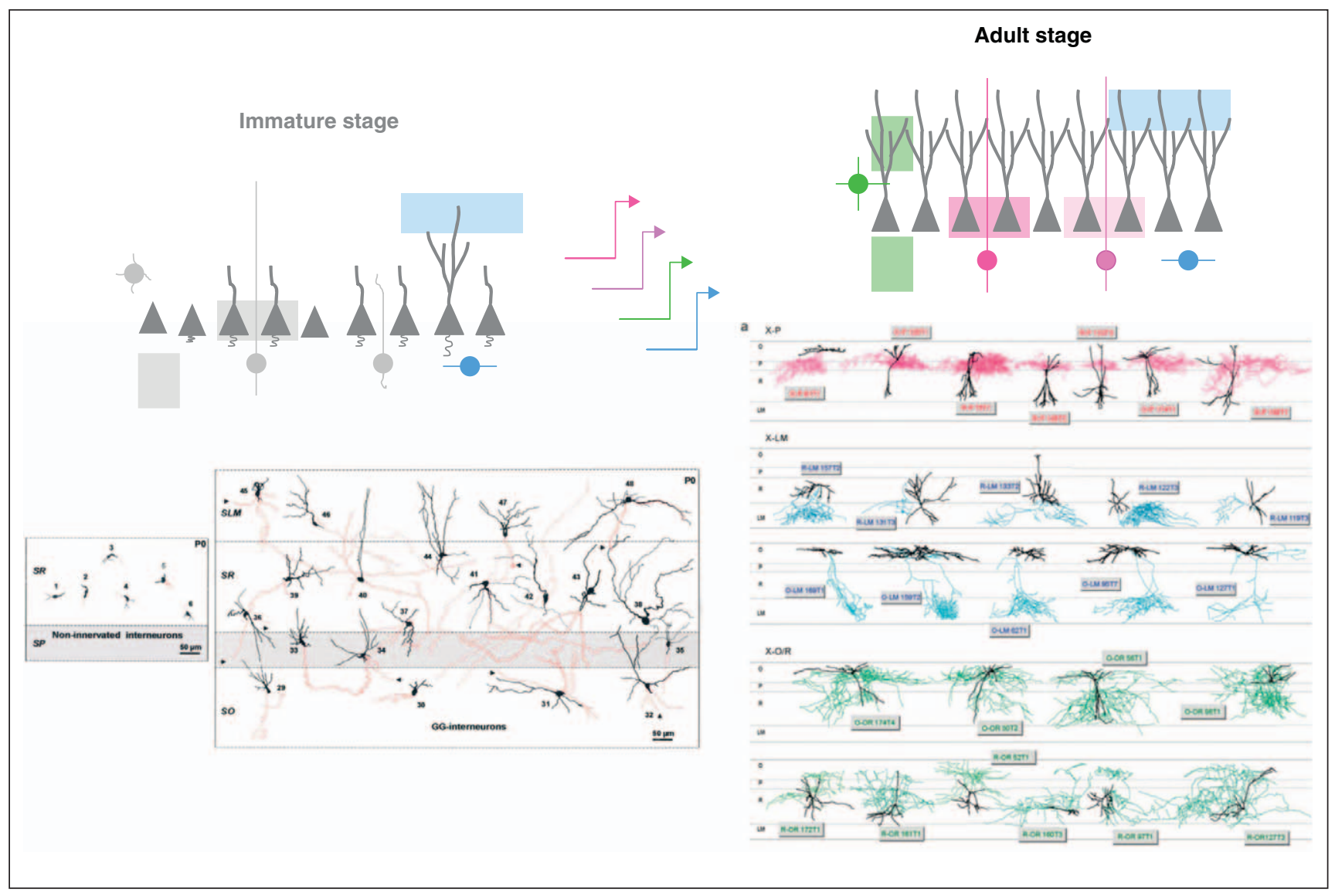

Bewildering diversity of the developing interneuron population. Schematic comparison between an immature developmental stage (left) for cortical interneuron networks (i.e. around birth in the rodent hippocampus) and the adult stage (right). At early stages of development, the developing interneuron network comprises (i) well-developed interneurons almost already displaying their adult morphological and neurochemical features (blue); (ii) interneurons with developed anatomical features but that do not express yet their characteristic neurochemical properties (gray future pink cell); (iii) neurochemically and morphologically immature interneurons. Interneurons that belong to the same family (like pink cells) may develop differently. Well developed interneurons already receive both GABAergic and glutamatergic inputs (GG-interneurons) whereas poorly developed cells are still not innervated as illustrated in the panels below taken with permission from [19]. Note that none of the reconstructed interneurons filled at P0 displays a recognizable morphology as compared to interneurons in the adult hippocampus (right panel) where different interneuron subtypes can be easily identified and classified according to their axonal arborisation (taken with permission from Cossart et al. Hippocampus 2006).

interneuron population pioneers cortical development, as the peak of genesis for GABAergic cells takes place a couple of days before that of their glutamatergic counterparts in rodents [13]. Cortical GABAergic neurons, at least in nonprimate vertebrates, are generated in the subpallium, mainly from two transient structures, the medial and caudal ganglionic eminences [14-16] but also from the preoptic area $\left[17^{\circ}\right]$. Among them, some GABAergic neurons are postmitotic and start migrating tangentially towards the cortex as early as embryonic day $10\left[13,18^{\bullet}\right]$. Probably mostly because they constitute an older cell population, the morpho-physiological properties and firing activity of interneurons are globally more developed than those of glutamatergic cells within the same network during each stage of development. Hence the GABAergic network is already operative in utero in the CA1 hippo- campal region at a time when glutamatergic cells are poorly developed morphologically and barely receive any synaptic input $\left[19^{\bullet}, 20\right]$. Regarding the maturation of their intrinsic excitability, it was recently shown that neocortical interneurons display a lower threshold for action potential generation than pyramidal cells at early postnatal stages [21] which confers them a higher probability to be recruited at the early phases of network synchronization [22]. Interestingly, the firing of immature hippocampal interneurons was also shown to be maintained at a high rate through specific regulatory mechanisms [23]. On the postsynaptic side, cortical GABAergic synapses mature on average before glutamatergic ones in most cell types ranging from pyramidal neurons and interneurons $\left[19^{\bullet}, 24,25^{\bullet}\right]$ to oligodendrocyte precursors [26], indicating a very general sequence 
Figure 2

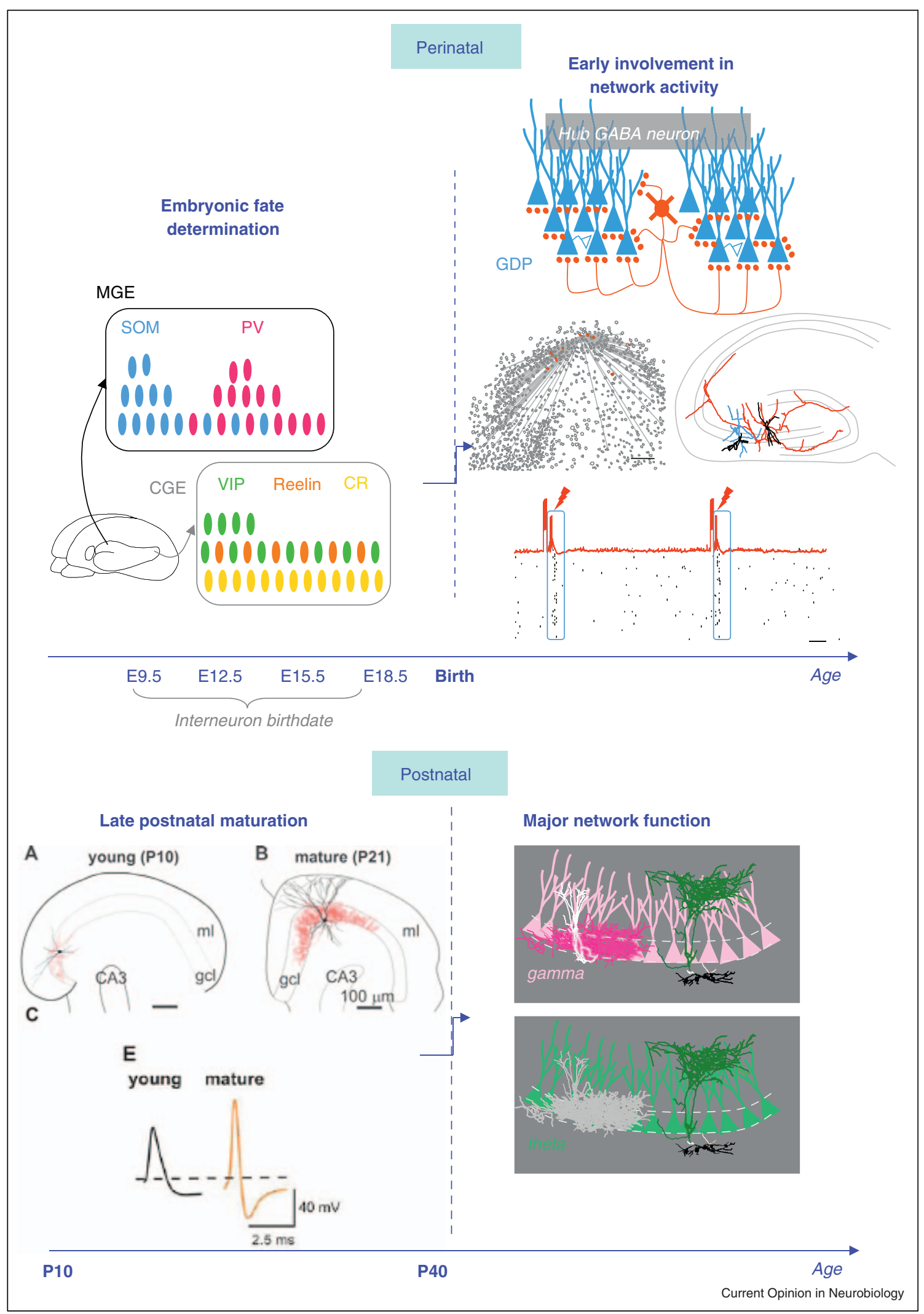


for the maturation of receptors. Given that this developmental sequence also holds for newborn neurons maturing in an adult environment [27], it likely reveals a mostly cell autonomous intrinsic sequence for receptor maturation. Along these lines, a direct inductive action of GABAergic transmission on AMPA-receptor development was recently demonstrated $\left[25^{\bullet \bullet}, 28,29\right]$ Pfeffer, $200915126 /$ id. However, it is important to stress that a differential maturation of GABAergic synapses is likely to occur along the somato-dendritic domain with probably a delayed development of somatic GABAergic synapses [24,30-32]. Therefore at least part of the GABAergic interneuron network starts operating a couple of days before the glutamatergic one, conferring a crucial network function to the interneuron population. Nevertheless, it is important to temper this statement by taking into account interneuron diversity since it is very likely that only specific subtypes of cortical GABAergic interneurons display an early functional maturation endowing them network function (see below).

The second major support for a key early network function of the developing interneuron population stems from the fact that GABAergic transmission depolarizes and excites neurons at early developmental stages due to a higher intracellular chloride content. Obviously, within a given developing structure, some neurons may be excited while others inhibited by GABAergic transmission depending on their intrinsic chloride load, as supported by the heterogeneity of intracellular chloride concentrations observed using chloride imaging techniques [33]. This observation is a very robust phenomenon observed throughout developing structures and species, resulting from a delayed maturation of chloride extruding transporters compared to importers [34]. Regarding depolarizing GABA actions it is important again to consider the developmental and morpho-physiological complexities of the interneuron population (Figure 1). First, the action of GABAergic transmission on a given pyramidal neuron is very likely to be highly dependent not only on the age of the postsynaptic neuron, but also on the type of presynaptic interneuron, even at nearby synapses [35-37]. Also, in agreement with an advanced stage of maturation, it is possible that older interneurons display a lower intracellular chloride concentration than pyramidal cells resulting in hyperpolar- izing GABAergic inputs [38] while younger interneurons will still be depolarized by GABAergic transmission $\left[39^{\bullet \bullet}, 40\right]$. This probably stems from the general increased expression of the chloride exporter KCC2 as a function of age in interneurons $\left[41^{\circ}\right]$. Particular interneuron subtypes, like NPY hilar interneurons, may even display a specific chloride homeostasis that further extends into adulthood [42].

A firm evidence in support of a central role of specific GABAergic microcircuits in synchronizing early neuronal activity is the recent finding that a few exceptional interneurons act as network 'hubs' that is high connectivity nodes gating information flow, through a dense axonal arborisation (Figure 2) and high intrinsic and synaptic excitabilities [43*0. Modifying the activity of a single hub neuron can synchronize (Figure 2) or desynchronize network dynamics depending on the type of hub neuron and on the state of the network. This indicates that the network function of hub neurons relies on a more complex chain of neuronal activation than a mere direct excitatory action of GABA. In fact, it remains to be determined whether excitatory GABAergic transmission is indeed a mandatory condition to hub function.

We have reviewed recent data indicating that the early maturation of GABAergic networks will endow some interneurons a unique early network function hence electing them as major contributors to activity-dependent development processes. However, it is probably equally important to stress that a reason for the particular susceptibility of the interneuron population to developmental insults, linking them to many brain disorders, is the long time span of interneuron development from in utero stages to puberty. Until when do interneurons continue developing? The critical period for GABAergic neuron maturation extends towards late postnatal stages in rodents maybe even after the stabilization of glutamatergic networks [44]. Hence, the electrophysiological properties of fast-spiking cortical interneurons develop until 40 postnatal days $\left(\left[45^{\circ}, 46\right]\right.$ and Figure 2$)$ while on the postsynaptic side, the structural and functional determinants of GABAergic synaptic transmission continue developing for similar time periods $\left[47,48^{\bullet}, 49\right]$. The continuous postnatal maturation of part of GABAergic networks may explain the late postnatal emergence of

(Figure 2 Legend) The long developmental journey of cortical GABAergic interneurons. (1) Schematic representation of different steps in the development of cortical GABAergic neurons from embryonic to adult stages. Top panel: Perinatal development from late embryonic to early postnatal stages. Left: Interneuron phenotypes are largely predetermined by their spatial and temporal embryonic origins with somatostatin (SOM) and parvalbumin (PV)-expressing cells mostly originating from the medial ganglionic eminences (MGE) whereas VIP, calretinin and Reelin-containing neurons are preferentially born in the caudal ganglionic eminences (CGE) as established in [18,63]. Right: Coherent network activity patterns emerge around birth and interneurons are central for the synchronization of neuronal activity. For example stimulation of hub GABA neurons, with a widespread axonal morphology (red) as compared to other interneurons at the same developmental stage (blue), synchronizes the activity of hundreds of cells as shown in the rasterplot below (adapted with permission from [43]). Bottom panel: Postnatal development of interneurons. Left: The morphophysiological properties of dentate gyrus basket-cells continue developing at late postnatal stages (taken with permission from [45]). Right: Schematic representation showing that in adult networks, different types of interneurons are differentially involved in the generation of network oscillations like gamma or theta rhythms. 
adult patterns of network dynamics [50,51] given the major contribution of GABAergic inputs in the emergence of sparse network spikes [52]. It also explains why some interneuron subtypes are particularly prone to postnatal environmental insults (see below). In fact, it may even well be that specific interneuron populations continue being generated throughout adulthood since the SVZ was shown to continue producing GABAergic interneurons postnatally [53].

\section{The strong genetic predetermination of interneuron subtypes facilitates interneuron developmental studies}

Given the major role of GABAergic networks in cortical development it is surprising that the morpho-physiological development of different GABAergic microcircuits as well as the emergence of their respective network function remains largely unknown. This is because the organization of the GABA neuron population is complex and even more difficult to study during development than adulthood (Figure 1). As extensively commented before [54], the connectivity of GABAergic microcircuits is amazingly organized. Although heterogeneous and complex, a general wiring diagram for adult cortical GABAergic networks can now be pictured as a result of a combined effort of several groups worldwide [10].

The description of similar functional connectivity maps in immature GABAergic microcircuits was until recently almost impossible because developing interneurons have not yet acquired the characteristic adult features used to classify them [55] (Figure 1); and they display an heterogeneous development as discussed above. One possible way to challenge this limitation is to use imaging approaches to map functional connectivity patterns [37,56-58]. Using a pairwise description of multineuron calcium activity combined to electrophysiology to reconstruct online the connectivity of developing hippocampal networks in mice where GABAergic neurons were GFPlabelled, the functional organization of the developing hippocampus was recently described $\left[43^{\bullet \bullet}\right]$. It was shown that the early postnatal CA3 region of the hippocampus displayed a scale-free mode of organization that is that the distribution of connections between neurons followed a power law [59] where 'hub' neurons were GABAergic interneurons displaying a widespread axonal arborisation, on average four times longer than the axonal length of other interneurons in the developing CA3 region of the hippocampus (Figure 2). It is important to stress how concepts from graph theory and statistical physics provide several useful models for the interpretation of imaging data to study the organization of complex dynamical systems such as developing neuronal networks. Still, if imaging approaches allow studying the general functional connectivity of developing GABAergic microcircuits without any a priori assumption regarding the importance of a particular interneuron subtype, they cannot easily address the development of precisely defined morphophysiologically interneuron families. However, this is now possible using 'genetic fate mapping' approaches.

As other developmental processes, the maturation of GABAergic functional microcircuits results from the interplay between intrinsic genetic programs and neuronal activity. Recent studies clearly indicate that the morpho-physiological identity of GABA neurons is strongly predetermined by their embryonic origin $\left[15,18^{\bullet}, 60^{\bullet \bullet}, 61-65\right]$. In other words, the adult phenotype of a given interneuron is largely dependent on where and when in the ganglionic eminences it was born (Figure 2). Hence, the cortical interneuron subtypes arising from the MGE and CGE are different $\left[60^{\bullet \bullet}, 61,66\right]$, the MGE producing mostly the parvalbumin-containing and somatostatin-containing neocortical interneurons while the CGE gives rise to calretinin-expressing and VIPexpressing cells $\left[15,18^{\bullet}, 60^{\bullet \bullet}, 63\right]$. It was also recently shown that two considered distinct hippocampal interneuron subtypes, Ivy and nitric oxide synthase positive neurogliaform cells are both derived from MGE progenitors under the control of Nkx2-1 [67 $]$. The strong embryonic predetermination of cortical interneuron identity carries implications that extend beyond the mere genetic analysis of interneuron development. Indeed, it can be applied as a tool to study different interneuron subtypes at an immature stage when they do not appear morpho-physiologically and neurochemically different yet using inducible genetic fate-mapping approaches [68]. Moreover, this spatio-temporal embryonic stamp is so robust that it could almost be proposed as a complementary way to reach a compelling classification of adult interneuron types, an even now problematic issue [55].

\section{When and how activity may influence interneuron maturation}

If interneuron diversity is largely predetermined by genetic programs, it is also well established that activity and environmental factors are equally important at every step of interneuron development, from early migration $\left[69^{\circ}, 70\right]$, postnatal cortical layer sorting $\left[41^{\bullet}\right]$, to late network integration $\left[30,41^{\circ}\right]$. Developing interneurons are particularly well designed to be directly influenced by activity. Hence, it was recently shown that actionpotential-independent release of GABA originating from developing cerebellar interneurons could be sensed by the presynaptic cells themselves in the form of 'preminis' [71], thus providing developing interneurons with a feedback 'private' source of GABA possibly serving their own maturation [30]. In addition, as discussed above, the development of cortical GABAergic microcircuits is a prolonged process, extending well into the postnatal period in rodents, a time window more likely to involve action-potential-dependent-neuronal activity. Indeed, the earliest forms of network electrical activity patterns appear postnatally in rodents $\left[72,73^{\bullet}\right]$. Accordingly, it was 
recently shown that early environmental stimulation accelerates the postnatal development of GABAergic neurotransmission and in particular the developmental decrease of intracellular chloride concentration [74 $4^{\bullet}$.

What type of activity may mostly contribute to GABAergic interneuron development? Activity in developing neurons is usually correlated between cells, in the form of spontaneous and recurrent calcium rises [75,76]. As reviewed elsewhere [76], a bewildering diversity of network dynamics and mechanisms have been described so far in developing neuronal structures. One possible way to simplify the picture is to classify early synchronous activity patterns according to the developmental stage at which they dominate cortical networks. Indeed, the maturation of coordinated activity patterns appears to follow a precise and coordinated developmental sequence, common to many developing structures. Hence, in both the hippocampus [73 ${ }^{\circ}$ ] and neocortex [77], correlated neuronal activity emerges around birth. It first synchronizes restricted gap-junction-coupled neuronal assemblies producing membrane potential oscillations associated with long-lasting calcium plateaus (Synchronous Plateau Assemblies - SPAs). Later, it involves large neuronal populations synchronized by synaptic transmission (Giant Depolarizing Potentials - GDPs; Figure 2). Given their specific spatial dynamics and associated calcium plateaus, SPAs could be proposed as playing a role in the consolidation of functional GABAergic microcircuits. Several observations indeed suggest that sustained elevations of intracellular calcium concentration encode a specific trigger signal to pathways regulating gene transcription $\left[78^{\circ}\right]$.

Given its postnatal emergence, electrical activity is certainly more likely to influence the development of latedeveloping rather than early-developing interneurons $\left[41^{\bullet}, 79\right]$. This may explain why the late maturing $\left[20,24,45^{\circ}\right]$, parvalbumin-containing perisomatic targeting interneurons are frequently pointed out in numerous developmental disorders $\left[5,9,48^{\bullet}, 80,81\right]$.

\section{Conclusion}

A new era for interneuron developmental studies has recently opened thanks to the combination of novel genetic and imaging approaches as well as to the increasing evidence that interneuron diversity may be embryonically predetermined. It is now possible to foresee interneuron diversity even at the earliest stages of cortical development. Developing interneurons support network function, maybe even more stronger than in adulthood. Their engagement in early network patterns is the seed for a proper development of cortical networks. But interneurons do not mature as a uniform unit; diversity also prevails upon their developmental journey. Hence the early maturation of some interneuron subtypes will endow them a crucial role in activity-dependent processes while the late maturation of others could confer them with a particular susceptibility to environmental and activity-dependent insults. Along these lines, it may well be that GABAergic hub neurons are born earlier than other interneuron subtypes, a hypothesis that could be addressed using fate-mapping approaches. A better understanding of interneuron functional diversity will certainly help the interpretation of their various maturation patterns. In any case, the diverse and long developmental journey of cortical interneurons largely explains the intimate links between determinants of GABA neuron proper development and brain disorders.

\section{Acknowledgements}

I thank all the 'Cossart team' members for helpful discussions and suggestions. I thank the FP7-ERC 'GABA Networks' grant (\#242842), the Fondation pour la Recherche Medicale, The Bettencourt-Schueller Foundation, the CNRS and the INSERM for financial support.

\section{References and recommended reading}

Papers of particular interest, published within the period of review, have been highlighted as:

- of special interest

-• of outstanding interest

1. Nosten-Bertrand M, Kappeler C, Dinocourt C, Denis C, Germain J, Phan Dinh TF, Verstraeten S, Alvarez C, Metin C, Chelly J et al.: Epilepsy in Dcx knockout mice associated with discrete lamination defects and enhanced excitability in the hippocampus. PLoS One 2008, 3:e2473.

2. Kerjan G, Koizumi H, Han EB, Dube CM, Djakovic SN, Patrick GN, Baram TZ, Heinemann SF, Gleeson JG: Mice lacking doublecortin and doublecortin-like kinase 2 display altered hippocampal neuronal maturation and spontaneous seizures. Proc Natl Acad Sci U S A 2009, 106:6766-6771.

3. Marsh E, Fulp C, Gomez E, Nasrallah I, Minarcik J, Sudi J, Christian SL, Mancini G, Labosky P, Dobyns W et al.: Targeted loss of Arx results in a developmental epilepsy mouse model and recapitulates the human phenotype in heterozygous females. Brain 2009, 132:1563-1576.

4. Yu FH, Mantegazza M, Westenbroek RE, Robbins CA, Kalume F, Burton KA, Spain WJ, McKnight GS, Scheuer T, Catterall WA: Reduced sodium current in GABAergic interneurons in a mouse model of severe myoclonic epilepsy in infancy. Nat Neurosci 2006, 9:1142-1149.

5. Di Cristo G: Development of cortical GABAergic circuits and its implications for neurodevelopmental disorders. Clin Genet 2007, 72:1-8.

6. Cobos I, Calcagnotto ME, Vilaythong AJ, Thwin MT, Noebels JL, Baraban SC, Rubenstein JL: Mice lacking DIx1 show subtypespecific loss of interneurons, reduced inhibition and epilepsy. Nat Neurosci 2005, 8:1059-1068.

7. Lewis DA, Hashimoto T, Volk DW: Cortical inhibitory neurons and schizophrenia. Nat Rev Neurosci 2005, 6:312-324.

8. Batista-Brito R, Machold R, Klein C, Fishell G: Gene expression in - cortical interneuron precursors is prescient of their mature function. Cereb Cortex 2008, 18:2306-2317.

A gene expression microarray analysis of interneuron precursors from the embryonic mouse neocortex, revealing that many transcription factors, neuropeptides, and cell surface genes selectively expressed in embryonic interneuron precursors are linked to autism, mental retardation, epilepsy and schizophrenia.

9. Batista-Brito R, Rossignol E, Hjerling-Leffler J, Denaxa M, Wegner M, Lefebvre V, Pachnis V, Fishell G: The cell-intrinsic requirement of Sox6 for cortical interneuron development. Neuron 2009, 63:466-481. 
10. Klausberger T, Somogyi P: Neuronal diversity and temporal dynamics: the unity of hippocampal circuit operations. Science 2008, 321:53-57.

11. Cardin JA, Carlen M, Meletis K, Knoblich U, Zhang F, Deisseroth $\mathrm{K}$

- Tsai LH, Moore Cl: Driving fast-spiking cells induces gamma rhythm and controls sensory responses. Nature 2009, 459:663-667.

Selective stimulation of PV interneurons in vivo in the mouse barrel cortex using light-driven channelrhodopsin activation generates gamma oscillations in the local cortical network and these gate sensory processing.

12. Olah S, Fule M, Komlosi G, Varga C, Baldi R, Barzo P, Tamas G:

-. Regulation of cortical microcircuits by unitary GABAmediated volume transmission. Nature 2009, 461:1278-1281.

A detailed morpho-physiological study showing how a particular subtype of cortical GABAergic neuron, the neurogliaform cell can provide longlasting inhibition of many neighbouring neurons without requiring a direct synaptic communication but by producing a cloud of GABA around their axonal fields.

13. Danglot L, Triller A, Marty S: The development of hippocampal interneurons in rodents. Hippocampus 2006, 16:1032-1060.

14. Anderson SA, Eisenstat DD, Shi L, Rubenstein JL: Interneuron migration from basal forebrain to neocortex: dependence on Dlx genes. Science 1997, 278:474-476.

15. Batista-Brito R, Fishell G: The developmental integration of cortical interneurons into a functional network. Curr Top Dev Biol 2009, 87:81-118.

16. Marin O, Rubenstein JL: A long, remarkable journey: tangential migration in the telencephalon. Nat Rev Neurosci 2001 , 2:780-790.

17. Gelman DM, Martini FJ, Nobrega-Pereira S, Pierani A, Kessaris N,

- Marin O: The embryonic preoptic area is a novel source of cortical GABAergic interneurons.

$J$ Neurosci 2009, 29:9380-9389.

The large majority of cortical interneurons originate from the medial and caudal ganglionic eminences. Nevertheless, this study shows that a third source, the embryonic preoptic area (POA) also contributes to a significant proportion of GABAergic neurons. Fate-mapping this population revealed that the $P O A$ is the origin of a small population of multipolar rapidly adapting GABAergic interneurons.

18. Miyoshi G, Butt SJ, Takebayashi H, Fishell G: Physiologically

- distinct temporal cohorts of cortical interneurons arise from telencephalic Olig2-expressing precursors. J Neurosci 2007, 27:7786-7798.

A genetic fate-mapping study of the temporal profile of the generation of different cortical interneuron subtypes originating from the MGE. Different morpho-physiological subtypes of MGE-derived interneurons are produced at particular developmental times.

19. Hennou S, Khalilov I, Diabira D,

- Ben Ari Y, Gozlan H: Early sequential formation of functional GABA(A) and glutamatergic synapses on CA1 interneurons of the rat foetal hippocampus. Eur J Neurosci 2002, 16:197-208.

Analysis of a large database collecting the morphological features and synaptic input properties of over 200 CA1 interneurons recorded at perinatal stages reveals that interneurons are on average much more developed than pyramidal cells at similar developmental stages since most of them already receive synaptic inputs at birth In addition, developing hippocampal interneurons are connected by GABAergic before glutamatergic synapses. Interestingly, 12 out of 162 morphologically described CA1 interneurons presented a long-range axonal arborisation that projected outside the CA1 area.

20. Gozlan H, Ben Ari Y: Interneurons are the source and the targets of the first synapses formed in the rat developing hippocampal circuit. Cereb Cortex 2003, 13:684-692.

21. Rheims S, Minlebaev M, Ivanov A, Represa A, Khazipov R, Holmes GL, Ben-Ari Y, Zilberter Y: Excitatory GABA in rodent developing neocortex in vitro. J Neurophysiol 2008, 100:609-619.

22. Rheims S, Represa A, Ben-Ari Y, Zilberter Y: Layer-specific generation and propagation of seizures in slices of developing neocortex: role of excitatory GABAergic synapses. J Neurophysiol 2008, 100:620-628.
23. Segerstrale M, Juuri J, Lanore F, Piepponen P, Lauri SE, Mulle C Taira T: High firing rate of neonatal hippocampal interneurons is caused by attenuation of afterhyperpolarizing potassium currents by tonically active kainate receptors. J Neurosci 2010 30:6507-6514.

24. Tyzio R, Represa A, Jorquera I, Ben Ari Y, Gozlan H, Aniksztejn L: The establishment of GABAergic and glutamatergic synapses on CA1 pyramidal neurons is sequential and correlates with the development of the apical dendrite. J Neurosci 1999, 19:10372-10382.

25. Wang DD, Kriegstein AR: GABA regulates excitatory synapse

- formation in the neocortex via NMDA receptor activation. $J$ Neurosci 2008, 28:5547-5558.

Using NKCC1 RNA interference knockdown in vivo, this study shows that GABA-induced depolarization, in cooperation with NMDA-R activation, is necessary for proper excitatory synapse formation and dendritic development of newborn cortical neurons.

26. Velez-Fort M, Maldonado PP, Butt AM, Audinat E, Angulo MC: Postnatal switch from synaptic to extrasynaptic transmission between interneurons and NG2 cells. J Neurosci 2010 30:6921-6929.

27. Markwardt SJ, Wadiche Jl, Overstreet-Wadiche LS: Inputspecific GABAergic signaling to newborn neurons in adult dentate gyrus. J Neurosci 2009, 29:15063-15072.

28. Wang DD, Kriegstein AR: Blocking early GABA depolarization with bumetanide results in permanent alterations in cortical circuits and sensorimotor gating deficits. Cereb Cortex 2010

29. Pfeffer CK, Stein V, Keating DJ, Maier H, Rinke I, Rudhard Y, Hentschke M, Rune GM, Jentsch TJ, Hubner CA: NKCC1dependent GABAergic excitation drives synaptic network maturation during early hippocampal development. $J$. Neurosci. 2009, 29:3419-3430.

30. Chattopadhyaya B, Di CG, Wu CZ, Knott G, Kuhlman S, Fu Y, Palmiter RD, Huang ZJ: GAD67-mediated GABA synthesis and signaling regulate inhibitory synaptic innervation in the visual cortex. Neuron 2007, 54:889-903.

31. Fiorentino $H$, Kuczewski N, Diabira D, Ferrand N, Pangalos MN Porcher C, Gaiarsa JL: GABA(B) receptor activation triggers BDNF release and promotes the maturation of GABAergic synapses. J Neurosci 2009, 29:11650-11661.

32. Marty S, Wehrle R, Varez-Leefmans FJ, Gasnier B, Sotelo C: Postnatal maturation of $\mathrm{Na}^{+}, \mathrm{K}^{+}, 2 \mathrm{Cl}^{-}$cotransporter expression and inhibitory synaptogenesis in the rat hippocampus: an immunocytochemical analysis. Eur $J$ Neurosci 2002, 15:233-245.

33. Glykys J, Dzhala VI, Kuchibhotla KV, Feng G, Kuner T, Augustine G, Bacskai BJ, Staley KJ: Differences in cortical versus subcortical GABAergic signaling: a candidate mechanism of electroclinical uncoupling of neonatal seizures. Neuron 2009, 63:657-672.

34. Ben-Ari Y, Gaiarsa JL, Tyzio R, Khazipov R: GABA: a pioneer transmitter that excites immature neurons and generates primitive oscillations. Physiol Rev 2007, 87:1215-1284.

35. Foldy C, Lee SH, Morgan RJ, Soltesz I: Regulation of fast-spiking basket cell synapses by the chloride channel CIC-2. Nat Neurosci 2010, 13:1047-1049.

36. Szabadics J, Varga C, Molnar G, Olah S, Barzo P, Tamas G: Excitatory effect of GABAergic axo-axonic cells in cortical microcircuits. Science 2006, 311:233-235.

37. Woodruff $A, X u$ Q, Anderson SA, Yuste R: Depolarizing effect of neocortical chandelier neurons. Front Neural Circuits 2009 , 3:15.

38. Banke TG, McBain CJ: GABAergic input onto CA3 hippocampal interneurons remains shunting throughout development. $J$ Neurosci 2006, 26:11720-11725.

39. Tyzio R, Minlebaev M, Rheims S, Ivanov A, Jorquera I, Holmes GL,

- Zilberter Y, Ben-Ari Y, Khazipov R: Postnatal changes in somatic gamma-aminobutyric acid signalling in the rat hippocampus. Eur J Neurosci 2008, 27:2515-2528. 
A developmental analysis of the depolarizing actions of GABA, from birth to 30 postnatal days, using non-invasive, somatic cell-attached recordings of GABA(A) and NMDA channels to monitor the GABA driving force and resting membrane potential respectively. The GABA driving force is found to be strongly depolarizing in most pyramidal neurons and interneurons during the first postnatal week in vitro as well as in vivo.

40. Sauer JF, Bartos M: Recruitment of early postnatal parvalbumin-positive hippocampal interneurons by GABAergic excitation. $J$ Neurosci 2010 , 30:110-115.

41. Miyoshi G, Fishell G: GABAergic interneuron lineages

- selectively sort into specific cortical layers during early postnatal development. Cereb Cortex 2010.

Using inducible genetic fate mapping approaches, this study addresses how MGE-derived and CGE-derived interneurons with comparable birthdates integrate different cortical layers at early postnatal stages. It is proposed that distinct interneuron subtypes are intrinsically programmed to respond differently to the cortical environment and integrate different target layers. In addition, this study shows that KCC2, a transporter responsible for the E/l shift in GABA actions is upregulated during the postnatal period of radial sorting.

42. Fu LY, van den Pol AN: GABA excitation in mouse hilar neuropeptide Y neurons. J Physiol 2007, 579:445-464.

43. Bonifazi $P$, Goldin M, Picardo MA, Jorquera I, Cattani $A$

-• Bianconi G, Represa A, Ben-Ari Y, Cossart R: GABAergic hub neurons orchestrate synchrony in developing hippocampal networks. Science 2009, 326:1419-1424.

Using calcium imaging of network dynamics in combination with online analysis and electrophysiological recordings, this study describes the functional connectivity of the developing hippocampus. It presents the first experimental evidence for highly connected, GABAergic 'hub neurons' essential for the coordination of Giant Depolarizing Potentials in the developing hippocampus.

44. Blue ME, Parnavelas JG: The formation and maturation of synapses in the visual cortex of the rat. II. Quantitative analysis. J Neurocytol 1983, 12:697-712.

45. Doischer D, Hosp JA, Yanagawa Y, Obata K, Jonas P, Vida I,

- Bartos M: Postnatal differentiation of basket cells from slow to fast signaling devices. J Neurosci 2008, 28:12956-12968.

A combined neuroanatomical, electrophysiological and computational analysis of the intrinsic and synaptic properties of dentate gyrus basket cells indicates that these cells continue developing postnatally until they become fast signalling devices.

46. Okaty BW, Miller MN, Sugino K, Hempel CM, Nelson SB: Transcriptional and electrophysiological maturation of neocortical fast-spiking GABAergic interneurons. J Neurosci 2009, 29:7040-7052.

47. Cruz DA, Lovallo EM, Stockton S, Rasband M, Lewis DA: Postnatal development of synaptic structure proteins in pyramidal neuron axon initial segments in monkey prefrontal cortex. J Comp Neurol 2009, 514:353-367.

48. Fazzari P, Paternain AV, Valiente M, Pla R, Lujan R, Lloyd K,

- Lerma J, Marin O, Rico B: Control of cortical GABA circuitry development by Nrg1 and ErbB4 signalling. Nature 2010, 464:1376-1380.

NRG1-ErbB4 signalling, a system linked to abnormal cortical operation in schizophrenia, is necessary for the proper development of glutamatergic synapses onto interneurons, and perisomatic and axo-axonic GABAergic synapses onto pyramidal neurons. Therefore this signalling pathway is essential for the correct wiring of GABAergic neurons during development.

49. Kobayashi M, Hamada T, Kogo M, Yanagawa Y, Obata K, Kang Y: Developmental profile of GABAA-mediated synaptic transmission in pyramidal cells of the somatosensory cortex Eur J Neurosci 2008, 28:849-861.

50. Colonnese MT, Kaminska A, Minlebaev M, Milh M, Bloem B, Lescure S, Moriette G, Chiron C, Ben-Ari Y, Khazipov R: A conserved switch in sensory processing prepares developing neocortex for vision. Neuron 2010, 67:480-498.

51. Rochefort NL, Garaschuk O, Milos RI, Narushima M, Marandi N, Pichler B, Kovalchuk Y, Konnerth A: Sparsification of neuronal activity in the visual cortex at eye-opening. Proc Natl Acad SciU $S$ A 2009, 106:15049-15054.
52. Wolfe J, Houweling AR, Brecht M: Sparse and powerful cortical spikes. Curr Opin Neurobiol 2010, 20:306-312.

53. Inta D, Alfonso J, von EJ, Kreuzberg MM, Meyer AH, van Hooft JA, Monyer $\mathrm{H}$ : Neurogenesis and widespread forebrain migration of distinct GABAergic neurons from the postnatal subventricular zone. Proc Natl Acad Sci U S A 2008, 105:20994-20999.

54. McBain CJ, Fisahn A: Interneurons unbound. Nat Rev Neurosci 2001, 2:11-23.

55. Ascoli GA, Onso-Nanclares L, Anderson SA, Barrionuevo G, Avides-Piccione R, Burkhalter A, Buzsaki G, Cauli B, DeFelipe J, Fairen $A$ et al.: Petilla terminology: nomenclature of features of GABAergic interneurons of the cerebral cortex. Nat Rev Neurosci 2008, 9:557-568.

56. Luo L, Callaway EM, Svoboda K: Genetic dissection of neural circuits. Neuron 2008, 57:634-660.

57. Marshel JH, Mori T, Nielsen KJ, Callaway EM: Targeting single neuronal networks for gene expression and cell labeling in vivo. Neuron 2010, 67:562-574.

58. Scanziani M, Haussesr M: Electrophysiology in the age of light. Nature 2009, 461:930-939.

59. Boccaletti S, Latora V, Moreno Y, Chavez M, Hwang D-U: Complex networks: structure and dynamics. Phys Rep 2006, 424:175-308.

60. Butt SJ, Fuccillo M, Nery S, Noctor S, Kriegstein A, Corbin JG,

-. Fishell G: The temporal and spatial origins of cortical interneurons predict their physiological subtype. Neuron 2005 , 48:591-604.

Morphological, neurochemical and electrophysiological characterization of mature cortical interneurons, derived from ultrasound-guided transplantation of EGFP-expressing MGE and CGE cortical progenitors into wild type hosts, provided the first in vivo demonstration that the mature morpho-physiological fate of transplanted cells is intrinsically predetermined by their embryonic place and time of origin.

61. Fogarty M, Grist M, Gelman D, Marin O, Pachnis V, Kessaris N: Spatial genetic patterning of the embryonic neuroepithelium generates GABAergic interneuron diversity in the adult cortex. $J$ Neurosci 2007, 27:10935-10946.

62. Butt SJ, Sousa VH, Fuccillo MV, Hjerling-Leffler J, Miyoshi G, Kimura S, Fishell G: The requirement of Nkx2-1 in the temporal specification of cortical interneuron subtypes. Neuron 2008, 59:722-732.

63. Miyoshi G, Hjerling-Leffler J, Karayannis T, Sousa VH, Butt SJ, Battiste J, Johnson JE, Machold RP, Fishell G: Genetic fate mapping reveals that the caudal ganglionic eminence produces a large and diverse population of superficial cortical interneurons. J Neurosci 2010, 30:1582-1594.

64. Wonders CP, Anderson SA: The origin and specification of cortical interneurons. Nat Rev Neurosci 2006, 7:687-696.

65. Xu Q, Cobos I, De La CE, Rubenstein JL, Anderson SA: Origins of cortical interneuron subtypes. J Neurosci 2004, 24: 2612-2622.

66. Xu Q, Tam M, Anderson SA: Fate mapping Nkx2.1-lineage cells in the mouse telencephalon. J Comp Neurol 2008, 506:16-29.

67. Tricoire L, Pelkey KA, Daw MI, Sousa VH, Miyoshi G, Jeffries B,

- Cauli B, Fishell G, McBain CJ: Common origins of hippocampa Ivy and nitric oxide synthase expressing neurogliaform cells. $J$ Neurosci 2010, 30:2165-2176.

Comparison of the developmental origins of two presumably different subtypes of hippocampal interneurons, the Ivy and NOS+ Neurogliaform cells, using a combination of genetic, molecular, immunohistochemical and electrophysiological techniques, indicates that these cells share a common embryonic origin. They may constitute a single interneuron subtype.

68. Miyoshi G, Fishell G: Directing neuron-specific transgene expression in the mouse CNS. Curr Opin Neurobiol 2006, 16:577-584.

69. Bortone D, Polleux F: KCC2 expression promotes the

- termination of cortical interneuron migration in a voltagesensitive calcium-dependent manner. Neuron 2009, 62:53-71. 
A study showing that Lhx6-interneurons migrating in cultures of cortical neurons change their responsiveness to GABA from a motogenic to a stop signal when GABA actions switch from depolarizing to hyperpolarizing after the developmental upregulation of the potassium-chloride cotransporter KCC2.

70. Manent JB, Jorquera I, Ben-Ari Y, Aniksztejn L, Represa A: Glutamate acting on AMPA but not NMDA receptors modulates the migration of hippocampal interneurons. $J$ Neurosci 2006, 26:5901-5909.

71. Trigo FF, Bouhours B, Rostaing P, Papageorgiou G, Corrie JE, Triller A, Ogden D, Marty A: Presynaptic miniature GABAergic currents in developing interneurons. Neuron 2010, 66:235-247.

72. Corlew R, Bosma MM, Moody WJ: Spontaneous, synchronous electrical activity in neonatal mouse cortical neurones. $J$ Physiol 2004, 560:377-390.

73. Crepel V, Aronov D, Jorquera I, Represa A, Ben-Ari Y, Cossart R: A

- $\quad$ parturition-associated nonsynaptic coherent activity pattern in the developing hippocampus. Neuron 2007, 54: 105-120.

An in vitro analysis of the maturation of population coherence in the developing CA1 region of the hippocampus showing that the first synchronous electrical neuronal activity patterns emerge at birth in the form of Synchronous Plateau Assemblies. The emergence of coherent neuronal activity is controlled by the actions of oxytocin, a maternal hormone released during labour.

74. He S, Ma J, Liu N, Yu X: Early enriched environment promotes - neonatal GABAergic neurotransmission and accelerates synapse maturation. J Neurosci 2010, 30:7910-7916.

This study analyses the effects of neonatal environmental enrichment on the electrophysiological and biochemical properties of GABAergic and glutamatergic transmission in the hippocampus. Early postnatal enrich- ment enhances GABAergic transmission and accelerates the $E / I$ shift in the actions of GABA

75. Allene C, Cossart R: Early NMDA-R-driven waves of activity in the developing neocortex: physiological or pathological network oscillations? J Physiol 2009, 588:83-91.

76. Blankenship AG, Feller MB: Mechanisms underlying spontaneous patterned activity in developing neural circuits. Nat Rev Neurosci 2010, 11:18-29.

77. Allene C, Cattani A, Ackman JB, Bonifazi P, Aniksztejn L, BenAri Y, Cossart R: Sequential generation of two distinct synapsedriven network patterns in developing neocortex. $J$ Neurosci 2008, 28:12851-12863.

78. Marek KW, Kurtz LM, Spitzer NC: cJun integrates calcium activity and tIx3 expression to regulate neurotransmitter specification. Nat Neurosci 2010, 13:944-950.

A study in neurons of the dorsal embryonic spinal cord of Xenopus tropicalis providing a mechanistic basis for early endogeneous calcium activity to regulate intrinsic genetic pathways that specify neurotransmitter choice in developing neurons at critical developmental time points.

79. de Lima AD, Gieseler A, Voigt T: Relationship between GABAergic interneurons migration and early neocortical network activity. Dev Neurobiol 2009, 69:105-123.

80. Belforte JE, Zsiros V, Sklar ER, Jiang Z, Yu G, Li Y, Quinlan EM, Nakazawa K: Postnatal NMDA receptor ablation in corticolimbic interneurons confers schizophrenia-like phenotypes. Nat Neurosci 2010, 13:76-83.

81. Do KQ, Cabungcal JH, Frank A, Steullet P, Cuenod M: Redox dysregulation, neurodevelopment, and schizophrenia. Curr Opin Neurobiol 2009, 19:220-230. 